\title{
Research on Cash Flow Incurrence-effect Incurred by Optimization of Firm Asset Structure*
}

\author{
Baifang Liu \\ Business School \\ Beijing Language and Culture University \\ Beijing, China 100083
}

\author{
$\mathrm{Li} \mathrm{Li}$ \\ Business School \\ Beijing Language and Culture University \\ Beijing, China 100083
}

\author{
Xuewei Zhan \\ Business School \\ Beijing Language and Culture University \\ Beijing, China 100083
}

\begin{abstract}
In this paper, cash flow incurrence-effect incurred by optimization of firm asset structure has been studied by Stacerberg Model. It has been shown in the game model that the company's capital structure optimization takes on income effect in oligopoly market, while capital effect in the perfectly competitive market. As market competition intensifies, incurrence-effect takes on the trend of transformation from income effect to capital effect.
\end{abstract} effect

Keywords-incurrence-effect; Stacerberg model; income

\section{INTRODUCTION}

Corporate cash flow is closely linked to asset structure. The future cash flows of enterprise presents different distribution characteristics with different asset structures. Even the capital structure of the two companies are identical, the value of corporate would be different because of different asset structures lead to different cash flow distribution, that is to say identical capital structure is not a sufficient condition for the same value of the company. MM theorem states that, in the ideal state of the economy, the value of the company's assets is independent of its capital structure. In the real state of the economy, MM theorem ignores the impact of the asset structure of the company's to its future cash flows, just from the the right side of accounting equation--the stakeholder to analyze the firm value thus limited its effectiveness of practical applications. The post capital structure theory expand the research horizons and began to notice the left factor of accounting equation --the impact of assets on the value of the company, it believes that corporate control rights, finished products market and competitive advantage influence the value of the company's assets. New Institutional Economics divided the corporate control rights into contractual control rights and residual control rights. Either of these all gives company management of the rights to adjust and optimize the structure of the company's assets.

*This Research findings is supported by the special fund of the basic research of the Central University, project number: 16ZDD01
With the optimization and adjustment of company management to the asset structure adjustment, the company's cash flow distribution changes accordingly: the distribution of cash flows may be turn to accelerate the recovery of cash flows during the early stage of investment and slow down the recovery of cash flows in the later stage of investment from uniformly distributed throughout the investment cycle; or on the contrary, slow down the recovery of cash flows in the early stage of investment and accelerate the recovery of cash flows in the later stage of investment.

This article called the phenomenon that managers pursuing the objective of maximizing corporate value, optimizing the structure of assets, resulting in decelerate recovery of cash flow in the early stage of investment and accelerate recovery of cash flow in the later stage of investment, cash flow presenting left-skewed distribution as the capital effect of asset structure optimization; while called the phenomenon that accelerate recovery of cash flow in the early stage of investment, decelerate recovery of cash flow in the later stage of investment and cash flow present rightskewed distribution as the income effect of asset structure optimization. As shown in Figure 1, the left is the capital effect diagram of asset structure optimization, while the right is the income effect diagram of asset structure optimization. In "Fig. 1", the horizontal axis represents the investment period " $t$ " while vertical axis represents cash flow " $c$ ". Capital effect and income effect is incurrence-effect caused by optimization of the asset structure on cash flow. 
Capital effects

Income effect

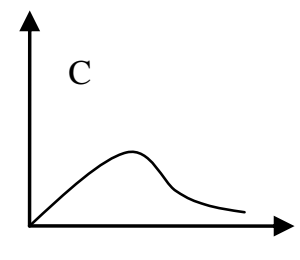

$\mathrm{t}$

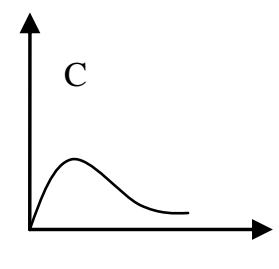

$\mathrm{t}$

Fig. 1. The analysis diagram of optimization effect of asset structure.

Asset pricing theory believes that the company values are its discounted value of future cash flows. Changes in the company's future cash flows result in a change in the company's value. "Fig. 1" shows asset structure optimization may be has capital effect and income effect, so the study of whether there is incurrence-effect and its impact factor is the task of this paper.

\section{THE PERFECTLY COMPETITIVE MARKET}

First, start the analysis from the perfectly competitive market. Assuming business in a perfectly competitive market, companies can only get an average market income. Investor's initial investment in the enterprise is $V_{0}$, the investment period is $\mathrm{T}(\mathrm{T}=1,2, \ldots \mathrm{N})$. Managers of enterprise operate and manage the investors' investment, transformed it into productive capital, liquidity, etc., forming a different asset structure. In the different mode that management selected, the corporate cash flow of each period is $\mathrm{Xt}(\mathrm{t})$.

Suppose the average rate of return is $i$, then $\Sigma \mathrm{X}_{\mathrm{t}}=\mathrm{V}_{0} * \mathrm{i}=\mathrm{C}$, where $\mathrm{C}$ is a constant, which means in a competitive market, the amount of cash flow that capital brought is constant. In perfectly competitive market, companies cannot get the excess economic profits, so that assumed all other conditions remain unchanged (e.g., effort of management), take no account of the time factor, then cash rewards that the specific investment gains is determined by the equilibrium interest rate market .

But the value of investment markets is different, suppose the market value of the initial investment $\mathrm{V}_{0}$ is $\mathrm{V}_{\mathrm{T}}$, according to the investment valuation formula:

$$
\begin{aligned}
& V_{T}=\sum X_{t}(1+i)^{-t} \\
& \text { s.t. } \sum X_{t}=V_{0} * i=C
\end{aligned}
$$

So, how can the management to optimize asset structure of the enterprise in order to make the market value of the investor's investment the largest? We solve the optimization problem consisted of the above two equations, obtain:

$$
X_{1}(1+i)^{-1}=X_{2}(1+i)^{-2}=\cdots X_{t}(1+i)^{-T}
$$

At that time $X_{1}(1+i)^{-1}=X_{2}(1+i)^{-2}=\cdots X_{t}(1+i)^{-T}, V_{T}$ obtain the maximum value, that is the market value of the investor's investment in the most. The optimum conditions can be obtained from the optimal constraints:

$$
\mathrm{X}_{1} \leq \mathrm{X}_{2} \leq \cdots \leq \mathrm{X}_{\mathrm{T}}
$$

If and only if the market interest rate $\mathrm{i}=0$, the optimal conditions holds. The optimization constraints indicate that when companies in a perfectly competitive market, the optimal asset structure that management selected has capital effect. When in a perfectly competitive market, managers cannot adjust and optimize through asset structure to gain short-term competitive advantage, thereby changing its longterm cash flow of the investment project; the management takes the way that makes cash flow to take a gradual increase of investment projects (Shown on the left in "Fig. 1") to optimize the capital structure and maximize the market value of investment projects. Therefore, in a perfectly competitive market, the way that manager to optimize the asset structure shows a capital effects phenomenon.

\section{OLIGOPOLY MARKET}

The following analyze the incurrence-effect that the asset structure optimization on cash flow under oligopoly market conditions. This article analyzes incurrence-effect under oligopoly market conditions by Stackelberg oligopoly competition model.

Assume there are two companies in the market : leading company $\mathrm{A}$ and trailing company $\mathrm{B}$. After receiving the investment funds $\mathrm{V}_{0}$, the two companies make Stackelberg oligopoly competition game. In the first period, the company A optimize its asset structure first, the result is its production reached $\mathrm{q}_{1}$, the company $\mathrm{B}$ observed A's output reached $\mathrm{q}_{1}$ after optimized asset structure, then the company B optimized its asset structure to produce the amount of $\mathrm{q}_{2}$. Apparently, according to our hypothesis, there is a correlation between corporate production and its asset structure optimization.

Assumption: When the production of company $A$ is $q_{1}$, its asset structure is $A_{\text {str }}^{1}$; When production of company $B$ is $q_{2}$, its asset structure is $A_{\text {str. }}^{2} \cdot A_{\text {str }}^{1}$ and $A_{\text {str }}^{2}$ represent the asset structure of company $\mathrm{A}$ and $\mathrm{B}$. This is a perfect information dynamic game. Suppose $Q_{1}=[0, \infty), Q_{2}=[0, \infty)$ that are $A^{\prime}$ production space and B's production space, namely the range of $\mathrm{q}_{1}$ and $\mathrm{q}_{2}$. Company B's strategy is a function from $\mathrm{Q}_{1}$ to $\mathrm{Q}_{2}$, that is $\mathrm{S}_{2}=\mathrm{Q}_{1} \rightarrow \mathrm{Q}_{2}$, the company A directly select the optimal asset structure in order to determine the production $\mathrm{q} 1$. The pure strategy equilibrium outcome of the game is $\left(\mathrm{q}_{1}, \mathrm{~S}_{2}\left(\mathrm{q}_{1}\right)\right)$, the payment function is $\mathrm{u}_{\mathrm{i}}\left(\mathrm{q}_{11}, \mathrm{~S}_{2}\left(\mathrm{q}_{1}\right)\right)$. Let the inverse demand function for the enterprise is $\mathrm{P}(\mathrm{Q})=\mathrm{k}-\mathrm{q}_{1}-\mathrm{q}_{2}, \mathrm{k}>0$, unit production costs of the two companies is $\mathrm{C}_{1}$ and $\mathrm{C}_{2}$ respectively, unit costs of asset structure optimization is $\mathrm{C}_{1 \mathrm{~A}}$ and $\mathrm{C}_{2 \mathrm{~A}}$, then the pay function is:

$$
\pi_{i}\left(q_{1}, q_{2}\right)=q_{i}\left(P(Q)-C_{i}-C_{i_{A}, i} i=1,2\right)
$$


Company B's question is:

$\operatorname{Max}_{2}\left(\mathrm{q}_{1}, \mathrm{q}_{2}\right)=\mathrm{q}_{2}\left(\mathrm{k}-\mathrm{q}_{1}-\mathrm{q}_{2}-\mathrm{C}_{2}-\mathrm{C}_{2 \mathrm{~A}}\right)$

$\mathrm{q}_{2} \geq 0$

Optimal conditions are:

$$
\mathrm{S}_{2}\left(\mathrm{q}_{1}\right)=\frac{1}{2}\left(\mathrm{k}-\mathrm{q}_{1}-\mathrm{C}_{2}-\mathrm{C}_{2 \mathrm{~A}}\right)
$$

Company A forecasts the output choice of company B is $\mathrm{q}_{2}$ based on strategy $\mathrm{S}_{2}\left(\mathrm{q}_{1}\right)$, then the problem in the first stage of company A is:

$$
\operatorname{Max}_{1}\left(\mathrm{q}_{1}, \mathrm{q}_{2}\right)=\mathrm{q}_{1}\left(\mathrm{k}-\mathrm{q}_{1}-\mathrm{S}_{2}\left(\mathrm{q}_{1}\right)-\mathrm{C}_{1}-\mathrm{C}_{1 \mathrm{~A}}\right), \mathrm{q}_{1} \geq 0
$$

To solve first-order conditions, there is:

$$
\mathrm{q}_{1}^{*}=\frac{1}{2}\left(\mathrm{k}+\mathrm{C}_{2}+\mathrm{C}_{2 \mathrm{~A}}\right)-\left(\mathrm{C}_{1}+\mathrm{C}_{1 \mathrm{~A}}\right)
$$

Plugging $\mathrm{q}_{1}^{*}$ in $\mathrm{S}_{2}\left(\mathrm{q}_{1}\right)$, there is :

$$
\mathrm{q}_{2}^{*}=\mathrm{S}_{2}\left(\mathrm{q}_{1}^{*}\right)=\frac{1}{4}\left[\left(\mathrm{k}+2 \mathrm{C}_{1}+2 \mathrm{C}_{1 \mathrm{~A}}\right)-3\left(\mathrm{C}_{2}+\mathrm{C}_{2 \mathrm{~A}}\right)\right]
$$

This is the Stackelberg equilibrium outcome. Earlier we set $A_{\text {gtr }}^{1}$ and $A_{\text {atr }}^{2}$ denote the asset structure of companies $A$ and $\mathrm{B}$, then $\mathrm{A}_{\mathrm{gtr}}^{1}$ * is company $\mathrm{A}$ 's optimal asset structure to obtain first-mover advantage , $\mathrm{A}_{\mathrm{gtr}}^{2}$ is the optimal asset structure for trailing company.

In order to compared whether there is incurrence-effect when management optimize asset structure in the oligopoly market conditions, we will simplify the Stackelberg equilibrium outcome above, assuming that the unit cost of production for both of the two companies is $\mathrm{C}$, the two companies can optimize the asset structure instantaneously, namely the cost of asset structure optimization is zero, there is $\mathrm{C}_{\mathrm{iA}}=0$. Plugging $\mathrm{C}_{\mathrm{i}}=\mathrm{C}$ and $\mathrm{C}_{\mathrm{iA}}=0$ into the equilibrium outcome, obtain:

$$
\begin{aligned}
& q_{1}^{*}=\frac{1}{2}(k-C) \\
& q_{2}^{*}=S_{2}\left(q_{1}^{*}\right)=\frac{1}{4}(k-C)
\end{aligned}
$$

As can be seen from the equilibrium outcome that the company A obtained first-mover advantage by optimizing asset structure and its output is twice of the trailing company's. Then optimal profits of the two companies are:

$$
\begin{aligned}
& \pi_{1}^{*}=\frac{1}{8}(k-C) \\
& \pi_{2}^{*}=\frac{1}{16}(k-C)
\end{aligned}
$$

Let the cash flow is the sole profit of the two companies-$\mathrm{A}$ and $\mathrm{B}$, then the optimal cash flow of the two companies are:

$$
\begin{aligned}
& C_{a s h 1}^{*}=\pi_{1}^{*}=\frac{1}{8}(k-C) \\
& C_{a s h 2}^{*}=\pi_{2}^{*}=\frac{1}{16}(k-C)
\end{aligned}
$$

Obviously, $\mathrm{C}_{\mathrm{ash1}}^{*} \geq \mathrm{X}_{1}^{*}$, this indicates that under conditions of oligopolistic competition, company A obtain the first-mover advantage by adjusting and optimizing its asset structure first, when compared to a perfectly competitive market conditions, there are more cash flow of company A in the first period.

The second part of the article focus on analyzing there is capital effect of asset structure optimization in the perfectly competitive market. While in oligopoly market, companies obtain first-mover advantage by maximizing their cash flow during the early stage of investment. However, when in the oligopoly market, whether there is capital effect of asset structure optimization cannot directly determine. Noting both of the initial investment of the two companies is $\mathrm{V}_{0}$, combined with the definition of oligopoly market; we can make reasonable inference that company A cannot get the cash flow which exceeds the initial optimal cash flow of the game in later phases on continuous basis. Then we can determine the cash flow distribution of company $\mathrm{A}$ is accelerate recovery of cash flow in the early stage of investment and decelerate recovery of cash flow in the later stage of investment, it presents right-skewed distribution. Therefore, we can determine in oligopoly markets, there is income effect of asset structure optimization.

The problem we must go deeply into a matter is: whether there is capital effect of the company B's asset structure optimization? If there is capital effect of asset structure optimization of company $\mathrm{B}$, then the conclusion we got before that there is income effect of asset structure optimization of enterprise will not have established under the oligopoly market. To solve this problem, we need to review the definition of incurrence-effect earlier proposed first. It emphasized the purpose of managers to optimize the structure is not the pursuit of capital effect and effect, but to maximize the value of the company. Both the capital effect and income effect are incurrence-effect in the process of optimizing the asset structure by managers. Managers of company $\mathrm{B}$ does not choose to maximize the value of the company as the target in the initial game, it actively optimize the asset structure and gain competitive advantage, therefore it does not comply with our definition of capital effects earlier. Assuming that in the next game, in order to pursue the maximization of corporate value, managers of company $B$ actively optimize its asset structure and constructed a credible threat (For example, the introduction of large-scale production equipment, established advanced production lines and clearly demonstrate its commitment to increase production ), then company A observed this signal and believes the threat of asset structure optimization of company 
$\mathrm{B}$ is credible, so the two companies will take the asset structure optimization strategy similar to that in a perfectly competitive market, then reach a conspiracy in later phases of the game and co-runs the market. The asset structure optimization of the two companies presented capital effect at this time. Previously, there is income effect of asset structure optimization of leading company whom pursue maximize the value of company.

The above is a simple explanation of equilibrium outcome of Stackelberg oligopoly competition model, then we continue to analyze when there is costs of asset structure optimization in the Stackelberg model, what is the necessary condition for company A to obtain leading superiority. Equilibrium outcome of the model is:

$$
\begin{aligned}
& \mathrm{q}_{1}^{*}=\frac{1}{2}\left(\mathrm{k}+\mathrm{C}_{2}+\mathrm{C}_{2 \mathrm{~A}}\right)-\left(\mathrm{C}_{1}+\mathrm{C}_{1 \mathrm{~A}}\right) \\
& \mathrm{q}_{2}^{*}=\mathrm{S}_{2}\left(\mathrm{q}_{1}^{*}\right)=\frac{1}{4}\left[\left(\mathrm{k}+2 \mathrm{C}_{1}+2 \mathrm{C}_{1 \mathrm{~A}}\right)-3\left(\mathrm{C}_{2}+\mathrm{C}_{2 \mathrm{~A}}\right)\right]
\end{aligned}
$$

Company A obtain leading superiority through structural optimization of assets, there are:

$$
\mathrm{q}_{1}^{*}-\mathrm{q}_{2}^{*}>0
$$

Thus : $\mathrm{C}_{1 \mathrm{~A}}<\frac{1}{6}\left[\mathrm{k}+5\left(\mathrm{C}_{2}+\mathrm{C}_{2 \mathrm{~A}}\right)\right]-\mathrm{C}_{1}$

Seen from the above constraints we can got that whether company A could obtain income effect of asset structure optimization depending on the comparison between its costs of asset structure optimization, its unit cost and the trailing company's costs of asset structure optimization and unit cost. Let the cost of company B is fixed, the manager's ability of company A to optimize the asset structure and its unit cost are negatively related. In other words, when the unit production costs of company A decreases, managers can more easily control the asset structure optimization cost, then it can get first-mover advantage; And when the unit production cost of company A increases, managers need to pay more effort to control the asset structure optimization costs in order to obtain first-mover advantage.

\section{CONCLUSION}

In this paper, we studied the incurrence-effect of asset structure optimization of enterprise to cash flow by using the Stackelberg model. And differ from the perfectly competitive markets, in the oligopoly markets, there is income effect of asset structure optimization of companies, while in a perfectly competitive market, there is capital effect of asset structure optimization. With the gradual improvement of market development, market competition is more and more intensively, income effect of asset structure optimization is more and more weakly, but the capital effect is growing. As market competition intensifies, and the market is maturing, incurrence-effect takes on the trend of transformation from income effect to capital effect.

\section{REFERENCES}

[1] Modigliani, Miller. 1958.Tthe cost of capital. Corporation finance and theory of investment[J]. American economic review, vol.(48):261297.

[2] Stulz,R. 1998 .Managerial control of voting rights: financing policies and the market for corporate control[J]. Journal of Financial Economics, (20):25-54

[3] Bolton P. and D. Scharfstein. A Theory of predation based on agency problems in financial contracting $[\mathrm{J}]$. American Economic Review, 1990, 80, 93-106.

[4] Maksimovic V. and Titman S. Financial reputation and reputation for product quality [J], Review of Financial Studies, 1991, 2, 175-200.

[5] Aghion P., Dewatripiont M. and Rey P. Renegotiation-design under unverifiable infermation[J]. Lead Article in Econometrica, 1994. 